\title{
Printing of Wearable Antenna on Textile
}

\author{
Rd. Khairilhijra Khirotdin ${ }^{1}$, Muhammad Adzeem Mahadzir ${ }^{2}$, Muhammad Musawwir M Nor Nazli ${ }^{3}$, Fauziahanim \\ Che Seman ${ }^{4}$, Samsul Haimi Dahlan ${ }^{5}$, Che Ku Afifah Che Ku Alam ${ }^{6}$ and Nurhaffizah Hassan ${ }^{7}$ \\ 1, 2, ${ }^{3}$ Faculty of Mechanical and Manufacturing Engineering, University of Tun Hussein Onn Malaysia, 86400 Parit Raja, Batu \\ Pahat, Johor, Malaysia \\ ${ }^{4,5,6}$ Faculty of Electrical and Electronics Engineering, University of Tun Hussein Onn Malaysia, 86400 Parit Raja, Batu Pahat, \\ Johor, Malaysia \\ ${ }^{7}$ Faculty of Engineering Technology, University of Tun Hussein Onn Malaysia, 84600 Pagoh, Muar, Johor, Malaysia
}

\begin{abstract}
A wearable antenna which is meant to be a part of the clothing used for communication purposes includes tracking, navigation and mobile computing has been seen in demand due to the recent miniaturization of wireless devices. Printing of conductive ink provides flexibility properties on electronics thus allowing it to be used on conformal surfaces. However, the current printing techniques mostly suffer from ink incompatibility and limited of substrates to be printed with. Hence, this paper intend to discloses the printing of wearable antenna using alternative technique via syringe-based deposition system with conductive ink on textile. A validation between simulation and measurement of return loss, $\left(\mathrm{S}_{11}\right)$ and radiation pattern of the antenna printed is also performed. It was found that a functional antenna is successfully printed on textile since the performances obtained are as expected. The antenna resonated at a minimum resonant frequency of $1.82 \mathrm{GHz}$ which the $\mathrm{S}_{11}$ gathered at $-18.90 \mathrm{~dB}$. The radiation pattern for both simulation and measurement is as predicted since both have a larger magnitude of the main lobe than the side lobe. The magnitude of the main lobe from measurement was observed to be $8.83 \mathrm{~dB}$ higher than the magnitude of the main lobe of the simulation which is only $3.77 \mathrm{~dB}$. It is proven that the syringe-based deposition system is capable of printing functional antenna on textile.
\end{abstract}

\section{Introduction}

Wearable electronic devices are becoming very popular in personal communications, computer systems and wireless monitoring of vital functions [1]. A main advantage of wearable antennas is that they are designed as elements of clothing able to transmit or receive wireless signals [2]. Integrating antennas into clothing can improve the desirability of such systems, and novel methods of fabricating conducting structures on textiles will be of benefit to diverse applications. Commonly, wearable antenna requirements for all modern application require light weight, low cost, almost maintenance-free and no installation [3]. Silver and copper conductive ink are frequently adapted by researchers in experimenting printed electronics due to its availability in market. Silver ink is used in this experiment because the conductivity properties are slightly better than copper ink. There are a lot of reports regarding the usage of conductive ink such as glass [4], printed circuit board [5], polyethylene terephthalate (PET) [6] and paper [7] via inkjet, flexography, aerosol and gravure respectively. However, most of these printing techniques only capable of printing on planar substrates and some of these techniques suffer from clogging as well as limited type of materials to be printed with [8] as reported in several previous study which is gas sensor via screen printing [9] and organic thin film transistors via inkjet printing $[10,11]$. Unlike the syringe deposition system, it is capable of printing electronics structure via strain gauge on both planar and non-planar substrates with variety of materials [12, 13]. The performance of printing the strain gauge on nonplanar substrates were also evaluated respectively [14]. Furthermore, the syringe deposition system provides larger building volume due to its nozzle movement that utilize three-dimensional coordinate axis system as well as can deposit wide range of viscosity level of ink, flexible and easy to handle. With the potential of this technique provides, an expansion of the usage particularly in printing antenna is worthwhile since there are no reports regarding the capability of syringe deposition system in fabricating a functional printed antenna on textiles. Besides, by realizing this, it will potentially open up a new scale of target market especially in the field of personal communications, computer systems and wireless monitoring of vital functions [1] and structural and health monitoring system.

* Corresponding author: adzeemmahadzir@gmail.com 


\section{Antenna Design}

\subsection{Specification of antenna design}

A type of micostrip patch antenna was first identified and selected and its detail dimension and shape was determined accordingly and modeled using AutoCAD software. Figure 1 shows the design of the antenna with its detail dimension respectively. The antenna is designed to be operated at resonance frequency of 1.575 $\mathrm{GHz}$ to fulfil the requirement set by Multimedia Communication and Malaysian Commission (MCMC) for rescue signal. There were four essential parameters to be specified including the operating frequency $\left(f_{0}\right)$, dielectric constant of substrate $\left(\varepsilon_{\mathrm{r}}\right)$, the height of the dielectric substrate $(h)$ and the thickness of the conductor patch ( $\mathrm{t}$ ) and Table 1 below shows the specification for each of the parameters considered.

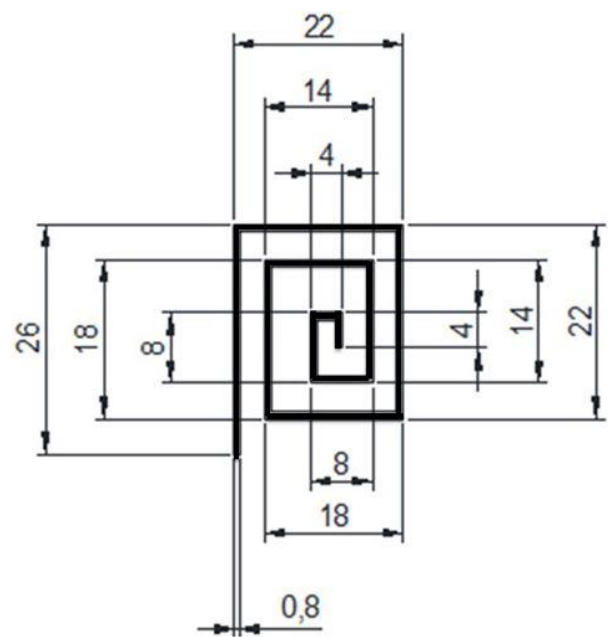

Fig. 1. Microstrip patch antenna design with its detail dimension (units in $\mathrm{mm}$ ).

Table 1. Specification of Antenna designed.

\begin{tabular}{|c|c|c|c|}
\hline Specification & $\begin{array}{c}\text { Width } \\
(\mathbf{m m})\end{array}$ & $\begin{array}{c}\text { Length } \\
(\mathbf{m m})\end{array}$ & $\begin{array}{c}\text { Thickness } \\
(\mathbf{m m})\end{array}$ \\
\hline $\begin{array}{c}\text { Silver conductive } \\
\text { ink track }\end{array}$ & 0.80 & 158.00 & 0.22 \\
\hline $\begin{array}{c}\text { Substrate } \\
\text { (polyester fabric) } \\
\text { with dielectric } \\
\text { constant, } \varepsilon_{\mathrm{r}}=1.6\end{array}$ & 30.00 & 30.00 & 0.15 \\
\hline Ground Plane & 30.00 & 30.00 & 0.11 \\
\hline
\end{tabular}

The total length of the antenna designed is $158 \mathrm{~mm}$ long with a $0.80 \mathrm{~mm}$ width and $0.22 \mathrm{~mm}$ thickness of the track.

\subsection{Simulation of Antenna Designed}

The antenna designed was initially simulated using Computer Simulation Technology (CST) Microwave Studio software to measure its resonance frequency as designed. The simulation process also is employed to determine the antenna return loss, $\mathrm{S}_{11}$ and to measure whether the antenna is radiated according to the pattern intended; omni-direction with bigger main lobe and smaller side lobe as required.

\section{Experiment}

\subsection{Deposition of ink and curing process}

An automatic syringe-based deposition system (Model: FISNAR 3-axis, F4200N.1) equipped with a teach pendant and industry's leading dispensing software is used to deposit the ink on textile substrate via polyester fabric as shown in Figure 2. The system has been widely used in electronic industries especially in solder paste machine and surface mount technology. A series of pilot tests were conducted to determine the range of suitable printing parameters and these printing exercises were performed with several range of printing parameters to determine the optimum printing parameter in order to obtain the desired dimension set previously. The dimensions are measured by taking an average from several points on the sample. The optimum printing parameter used is illustrated in Table 2. The other two parameters including a height deposition and nozzle diameter were set to be constant.

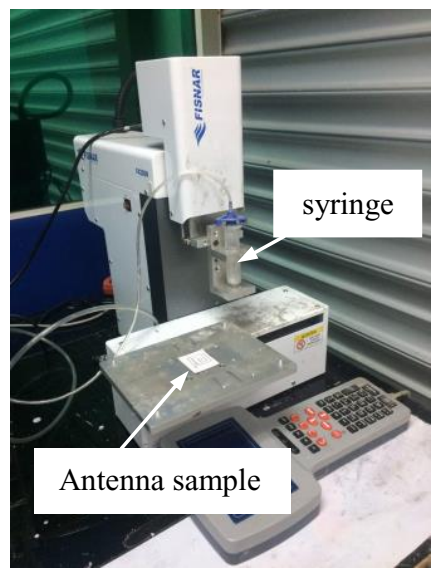

Fig. 2. Automated Syringe Deposition System.

Table 2. Optimum Printing and Curing Parameter selected.

\begin{tabular}{|c|c|c|c|c|}
\hline \multicolumn{5}{|c|}{ Printing Parameter } \\
\hline $\begin{array}{c}\text { Pressure } \\
(\mathbf{k P a})\end{array}$ & $\begin{array}{c}\text { Speed } \\
(\mathbf{m m} / \mathbf{s})\end{array}$ & $\begin{array}{c}\text { Height } \\
\text { Deposition } \\
(\mathbf{m m})\end{array}$ & $\begin{array}{c}\text { Nozzle } \\
\text { Diameter } \\
(\mathbf{m m})\end{array}$ & $\begin{array}{c}\text { Viscosity } \\
\text { of ink } \\
(\text { Pa.s) }\end{array}$ \\
\hline 175 & 25.00 & 1.20 & 0.51 & 2.40 \\
\hline \multicolumn{4}{|c|}{ Curing Parameter } \\
\hline \multicolumn{2}{|c|}{ Temperature $\left({ }^{\circ} \mathbf{C}\right)$} & \multicolumn{3}{c|}{ Time (minutes) } \\
\hline \multicolumn{2}{|c|}{160} & \multicolumn{3}{c|}{45.00} \\
\hline
\end{tabular}


A curing process is then employed using an oven (Memmert model 100-800) to reduce the percentage of unwanted material in conductive ink since conductive ink; either oil-based or contain water or solvents is mundanely comes in liquid and needs to be cured usually by heating process to expose its metallic contents [15]. The curing process played an important role to provide a good conductivity of the ink tracks. Oven is used as a curing process since it provides a consistent and stable temperature and the samples could be cured at a higher temperature if needed. In addition, oven is easy to set up by simply adjust the timer and the temperature gauge. Several pilot tests as well were previously performed to determine the optimum curing parameters that result in the lowest resistance. The optimum curing parameter selected is depicted in Table 2 previously shown. A total of ten samples were printed from the simplification method made using Taguchi method. Figure 3 shows the antenna that had been successfully printed using the syringe deposition system and cured with oven.

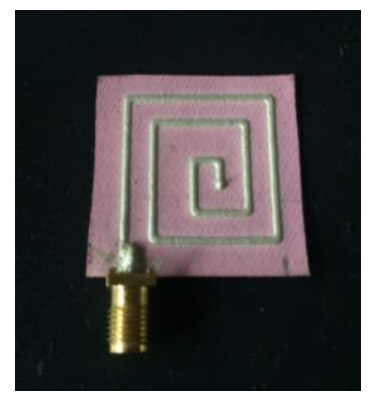

Fig. 3. Microstrip patch antenna printed using syringe deposition system and cured with oven

\subsection{Material and substrate}

A conductive ink used throughout the whole study is silver epoxy-based ink material (Model: AG806) as shown in Figure 4 and direct usage of the ink is not possible due to high solid fraction thus an adjustment of viscosity via dilution with Toluene solvent is necessary. The fabric material used is made of polyester and since the aim is to embed antenna on a life jacket, polyester material is much suitable because it mimics the actual fabrics made for life jackets.

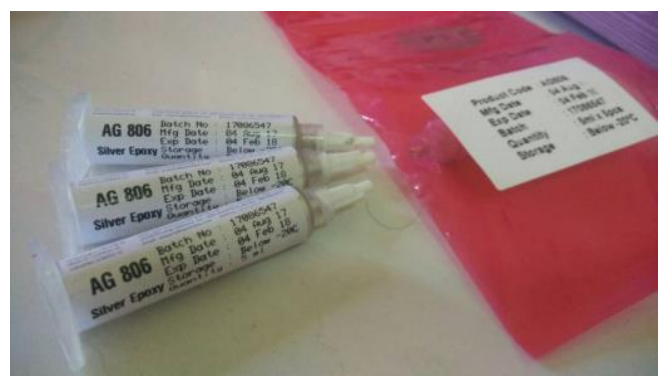

Fig. 4. Silver-epoxy based ink (Model: AG806)

\subsection{Measurement}

Analysis of the antenna printed is consisted of the measurement of the line width and thickness of the ink track using an optical microscope and its electrical properties via inductance (L), capacitance (C) and resistance (R) (LCR) meter. A cross-sectional area of the ink track and its total length were determined to calculate the resistivity. A measurement of resonance frequency and return loss $\left(\mathrm{S}_{11}\right)$ of the antenna were measured using Vector Network Analyzer (VNA) (Model: Rohde \& Schwarz ZVB14). The samples were then tested in semi-anechoic chamber to measure its radiation pattern.

\section{Results}

\subsection{Simulation}

An electromagnetic performance of the antenna is performed numerically in time domain solver using CST Studio software. The simulated return loss $\left(\mathrm{S}_{11}\right.$ parameter) of the antenna is shown in Figure 5. The figure implies that the antenna radiates best at 1.575 $\mathrm{GHz}$ as designed (indicated by dash line). The magnitude of the antenna is found to be $-14 \mathrm{~dB}$. In the meantime, the simulated radiation pattern of the antenna designed is depicted in Figure 6 where the farfield directivity of the antenna is observed to be $3.77 \mathrm{~dB}$ at $1.575 \mathrm{GHz}$ with the main lobe direction is 5.0 degree. Furthermore, according to the radiation pattern, the side level of the antenna is $-2 \mathrm{~dB}$. Both results prove fulfilled the requirement for antenna designed previously.

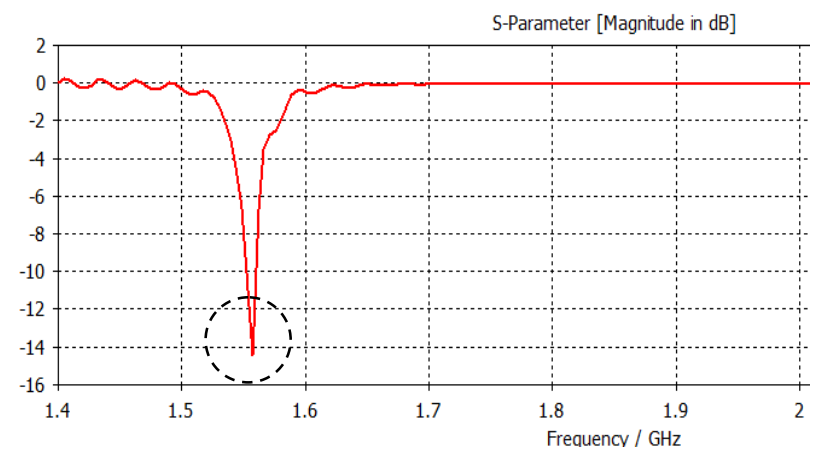

Fig. 5. Simulated return loss $\left(S_{11}\right)$ of the antenna 
Farfield Directivity Abs (Phi=90)

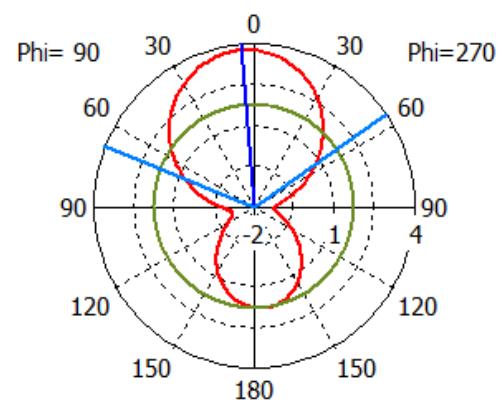

Theta / Degree vs. dBi

Fig. 6. Simulated radiation pattern of the antenna

\subsection{Measurement of resonance frequency, return loss $\left(S_{11}\right)$ and radiation pattern}

The measurement of the antenna was conducted to validate the simulated result made earlier. The resonance frequency of the fabricated antenna was determined using VNA as shown in Figure 7 below. The return loss $\left(\mathrm{S}_{11}\right.$ parameter) of the antenna is also measured accordingly and the result is illustrated in Figure 8. The result indicates that the antenna radiates best at 1.824 $\mathrm{GHz}$ with a magnitude of $-18.896 \mathrm{~dB}$.

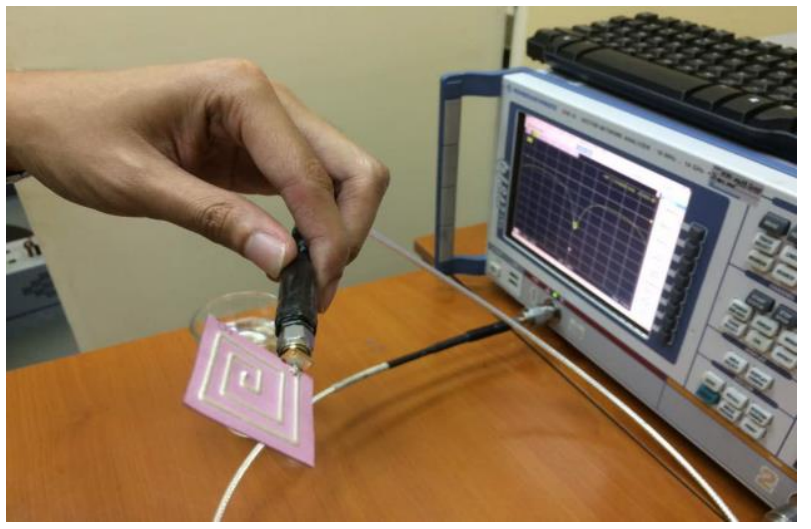

Fig. 7. Measurement of return loss of the antenna using VNA.

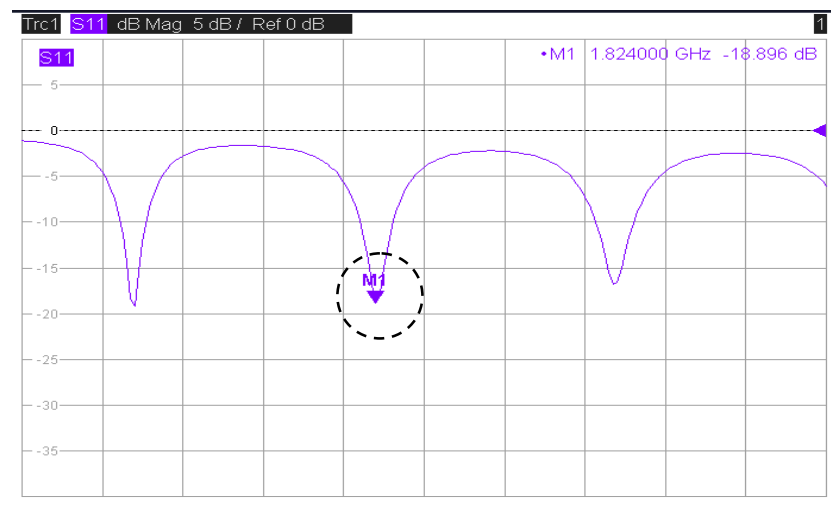

Fig. 8. Measurement result of the return loss of the antenna
A far-field radiation patterns result of the antenna was measured in the semi-anechoic chamber. The antenna was aligned first to a horn antenna with adjustable polarization. Figure 9 (a) and (b) show the position of the antenna and the horn antenna during measurement of radiation pattern performed in the semianechoic chamber. The result of the radiation pattern measurement is depicted in Figure 10 where the condition indicates that the antenna designed has an omnidirectional directivity at $1.824 \mathrm{GHz}$. The farfield directivity is observed to be of $8.83 \mathrm{~dB}$ magnitude. The main lobe direction is 6.3 degree and the side level magnitude of the antenna is $5.78 \mathrm{~dB}$.

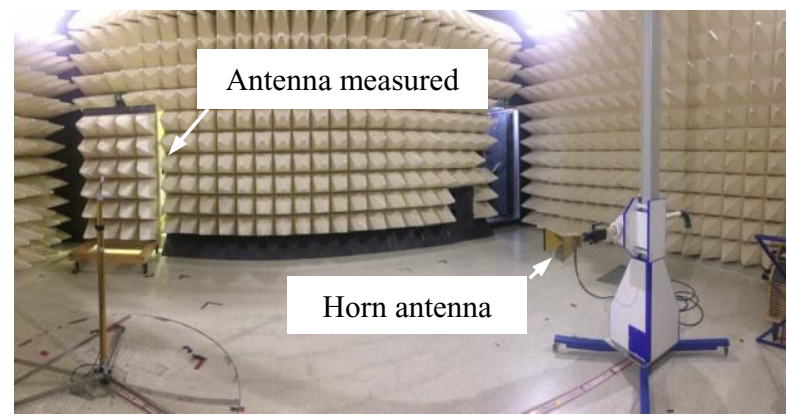

(a)

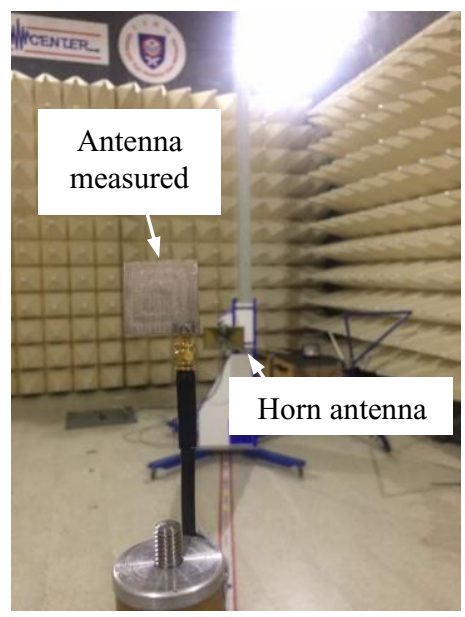

(b)

Fig. 9. Position of antenna and horn antenna during measurement (a) side view (b) antenna facing horn antenna

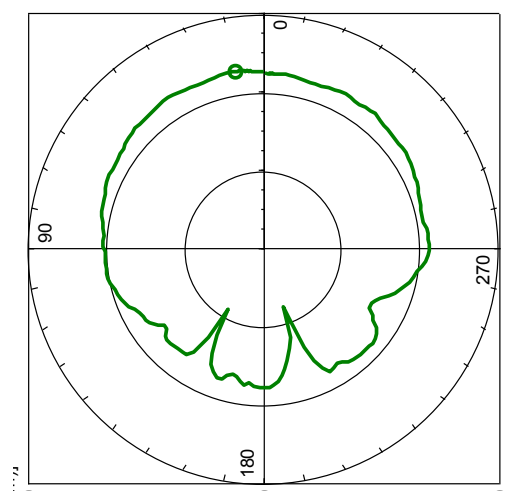

Fig. 10. Measurement result of the radiation pattern of the antenna 


\section{Discussion}

From the simulation, the frequency of the designated wearable antenna operated at $1.575 \mathrm{GHz}$ but in measurement, the resonance frequency measured is shifted to $1.824 \mathrm{GHz}$. The slight difference observed is might due to the imperfect soldering process that makes the unmatching condition on the port. The return loss $\left(\mathrm{S}_{11}\right.$ parameter $)$ from the simulation resulted in a magnitude of $-14 \mathrm{~dB}$ while in measurement, the return loss is $-18.896 \mathrm{~dB}$. The return loss of both simulation and measurement was passed below $-10 \mathrm{~dB}$ and it means that more than $10 \%$ of the incident power is reflected back towards the source from the antenna as required. The performance of the printed antenna is considered better in performance since the return loss of the measurement gives a higher return loss. In addition, the radiation pattern for both simulation and measurement gave a good result since both have a larger magnitude of the main lobe than the side lobe. The magnitude of the main lobe from measurement was observed to be 8.83 $\mathrm{dB}$ higher than the magnitude of the main lobe radiation pattern of the simulation which is only $3.77 \mathrm{~dB}$. The difference between the simulation and the measurement may due to the manufacturing tolerance especially on soldering the SMA connector to the track which is result in imperfect connection in transmitting the signal. Besides, a cross-sectional shape of the antenna track from simulation is drawn in rectangular shape to replicate the conventionally fabricated antenna while in measurement the resultant cross-sectional shape of the ink track deposited by the syringe deposition system is always in semi-circular shape. There is a potential of this semi-circular shape in producing a better result in antenna performance as observed from the aforementioned results. A more thorough investigation on the effect on these two different cross-sectional shapes of the ink track should be performed to validate the produced results.

\section{Conclusion}

In summary, the wearable antenna printed is able to operate near its designated frequency. It was also observed that several factors caused a slight difference in simulation and measurement results due to imperfect soldering that makes unmatching condition on the port. Another difference perceived is the cross-sectional shape of the ink track designed where the actual cross-sectional shape of the fabricated antenna is not the same with the designed ink track of the antenna in simulation. These two factors were found to be the main reasons of the slight difference on the results between simulation and measurement. However, the results from measurement offers a better performance in antenna performance since the return loss, $S_{11}$ parameter and the magnitude of the main lobe of radiation pattern is higher than the simulation. Besides, from the results gathered, it had proven that the syringe-based deposition system is capable of fabricating a functional electronics structure particularly antenna since the wearable antenna printed showing a good results. The antenna could operate and radiate at its designated frequency thus, it will potentially open up another dimension in communication and might become a life saver in the near future. A further investigation on the antenna performance especially in various conditions including bending and wet condition is highly recommended.

\section{References}

[1] H. Adel, R. Wansch, C. Schmidt, Antennas and Propagation Society International Symposium, 2003.IEEE, 1, 471, ST-Antennas for a body area network (2003)

[2] E. G. Lim, Z. Wang, J. C. Wang, M. Leach, R. Zhou, C. U. Lei, K. L. Man, Eng. Lett., 22, 2, 94-101 (2014)

[3] N. H. M. Rais, P. J. Soh, F. Malek, S. Ahmad, N. B. M. Hashim, P. S. Hall, Loughborough Antennas and Propagation Conference, LAPC 2009 - Conference Proceedings, 225-228 (2009)

[4] M. Inoue, Y. Tada, H. Muta, Y. Hayashi, T. Tokumaru, 14th International Conference on Electronic Materials and Packaging, EMAP 2012 (2012)

[5] K. V. Abhinav, R. Rao, V. K. Karthik, S. P. Singh, RSC Adv., 5, 79, 63985-64030 (2015)

[6] E. Halonen, T. Viiru, K. Ostman, A. L. Cabezas, M. Mantysalo, IEEE Trans. Components, Packag. Manuf. Technol., 3, 2, 350-356 (2013)

[7] R. Lakhmi, H. Debeda, I. Dufour, C. Lucat, IEEE Sens. J., 10, 6, 1133-1137 (2010)

[8] S. Laschi, I. Palchetti, M. Mascini, Sensors Actuators, B Chem., 114, 1, 460-465 (2006)

[9] A. S. G. Reddy, B. B. Narakathu, M. Z. Atashbar, M. Rebros, E. Hrehorova, B. J. Bazuin, M. K. Joyce, P. D. Fleming, A. Pekarovicova, Sens. Lett., 9, 2, 869-871 (2011)

[10] J. Li, B. An, J. Qin, Y. Wu, Proceedings International Symposium on Advanced Packaging Materials, 91-93 (2011)

[11] A. S. G. Reddy, B. B. Narakathu, M. Z. Atashbar, M. Rebros, E. Rebrosova, M. K. Joyce, Procedia Engineering, 25, 956-959 (2011)

[12] R. K. Khirotdin, N. Hassan, H. H. Siang, and M. H. Zawahid, Engineering Letters, 25, 3 (2017)

[13] R. K. Khirotdin, M. I. S. M. Zainuri, A. I. Ishak, N. Hassan, K. Kamarudin, M. R. Ibrahim, R. A. Haq, M. Ibrahim, N. Sau'de, O. M. F. Marwah, $8^{\text {th }}$. International Conference of Mechanical and Manufacturing Engineering, Langkawi, Malaysia (2017) (to be published)

[14] K. Khirotdin, M. F. Ngadiron, M. A. Mahadzir, N. Hassan, Material Science \& Engineering Conference Series, 226, 1, 012019 (2017)

[15] S. Ahmed, Polymer and Science: Coatings and Adhesives (2007) 